\title{
The Southeast Asian Dendro Workshop 1998 (SEA Dendro 98)
}

Chiang Mal, Thailand, February 16-20, 1998

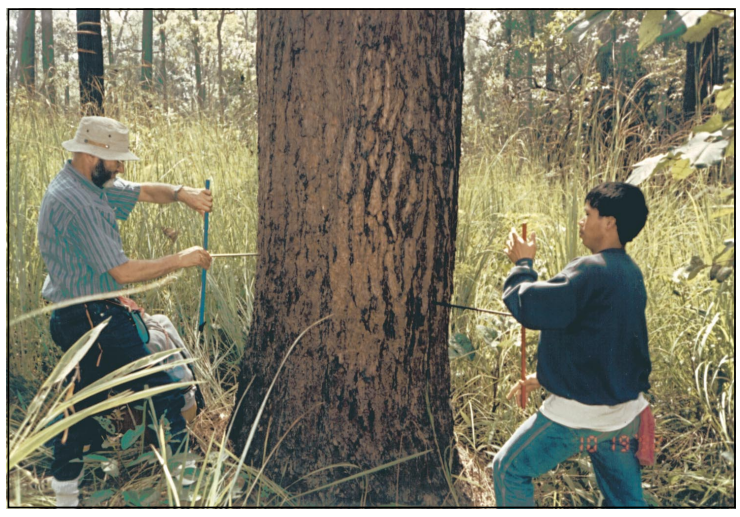

The principal goal of this conference was to foster communication, collaboration and exchange of information and ideas among scientists actively involved or interested in the development and analysis of tree-ring and other paleorecords for paleoclimatic studies in Southeast Asia and the vicinity. Such data are very sparse for vast areas of this region of the Pole-Equator-Pole (PEP) II transect, for both PAGES time streams I and II. There is thus

Coring old-growth Pinus merkusii from Thung Salaeng Luang National Park in northcentral Thailand (Photo: M. Barbetti)

PEP II, continued from previous page sentation for the region, had been agreed. The outcome was 30 proposed PFT's and 23 biomes. These were compared to the established Biome 6000 biomes. Dr. Liz Pickett was able to present these at the BIOME 6000 meeting in Jena, Germany, October 1998, along with the modern and fossil assembled data series as part of the region's overall contribution to the BIOME 6000 project.

The 3 days were clearly productive and many participants were involved in a PAGES project for the first time. The lively discussion brought home the value of this kind of comparative exercise in allowing a refining of interpretations of climatic change data from a substantial body of existing and growing proxy-data across the region. There are now many new data series coming online from South East Asia [see for example the following report by $\mathrm{D}^{\prime}$ Arrigo], and these are particularly welcome as they fill a large gap identified from the earliest days in setting up the PEP II program. The meeting was also seen as an important link to other groups such as the Southern Connections, Australasian Quaternary Association and the Institute of Australian Geographers. The meeting was generously supported by PAGES and the University of Western Australia.

\section{John Dodson}

Department of Geography, University of Western Australia, Perth, Australia

johnd@geog.uwa.edu.au a critical need to expand the existing database for Southeast Asia and adjacent sites. Tree-ring records were the main emphasis of the meeting, although other paleoclimatic and historical data were discussed. The meeting brought together some 50 scientists from 15 nations, many of whom had not had the opportunity to attend an international conference in the past. Both oral communications and posters were presented. The meeting succeeded in summarizing the state of the art for dendrochronology in Southeast Asia and vicinity and in identifying key scientific questions and needs for successful future research efforts in the region, including efforts to reconstruct large-scale climatic change. It was thus highly successful in advancing the interests of PAGES/PEP II as well as ESH, ARTS, CLIVAR, START and other initiatives. Below is an overview of the meeting.

\section{Introductory Presentations}

The governor of Chiang Mai opened the meeting with a Buddhist ceremony. Several introductory presentations provided an overview of the climate of Southeast Asia based on instrumental data, including Asian monsoon and ENSO variability and ENSO-monsoon interactions in the Southeast Asian region. A state of the art review of tropical dendrochronology set the stage for the tree-ring papers. Another keynote presentation discussed the ecophysiology and forest dynamics of tropical forest trees in Thailand and elsewhere in Southeast Asia.

\section{Southeast Asia}

A series of presentations highlighted recent tree-ring studies in Thailand, focusing on the development of teak and mountain pine tree-ring chronologies and their links to monsoon climate and historical data. Other Thailand work presented included radiocarbon variations in mountain pine tree-ring records and discussion of forest physiology, ecology and stand dynamics modeling, and human disturbance. Papers were also given on the development of teak records in Indonesia and their use in paleo-ENSO studies, including reconstructions of the Southern Oscillation Index (SOI). Another paper reported on the development of density tree-ring records from Laos.

\section{North and East Asia}

Several papers outlined recent tree-ring studies in northern and eastern Asia. For Mongolia, presentations were given on the use of tree-ring data to reconstruct temperature and precipitation (drought). The climatic response of tree growth to monsoon rainfall, snowfall, winter temperature and other factors was identified in treering data from South Korea, China, Japan, and Taiwan.

\section{Western Asia}

Studies were also presented from Western Asia, including the high elevation areas of Tibet, Nepal and India. For Tibet, there was discussion of the potential for use of tree rings from drought-sensitive trees for reconstruction of monsoon activity; for $\mathrm{Ne}-$ pal, the development of chronologies, growth patterns and links to monsoon climate were discussed, for India there was discussion of teak and other tree-ring records and their response to monsoon precipitation.

\section{Other Tropical Regions}

There were also presentations on tree-ring studies in tropical regions outside of Asia: in Brazil x-ray identification of growth ring features in Araucaria, and in Zimbabwe identification of suitable tree species for dendrochronology.

\section{Recommendations for Future Work}

Future collaborative efforts between dendrochronologists from Asia and western nations need to include the establishment of tree-ring laboratories in Asia (as has already been initiated in Nepal, Thailand and Mongolia), coordinated field expeditions, and the writing of combined proposals and papers. Memoranda of Under- 
standing (MOUs) can be very useful in facilitating field efforts, as has been demonstrated in Nepal, Mongolia, and other Asian sites.

Some of the largest gaps in coverage of tree-ring and other high resolution paleoclimatic data are found in the tropics. Sites where there is pronounced seasonality, and suitable tree species with annual rings and sufficient longevity thus need to be identified. Basic strategies for successful development of tropical tree-ring chronologies were discussed. Emphasized was the importance of accurate cross-dating, which is critical for establishment of annual ring structure and to ensure precise dating of difficult tropical species. Relatively few tree species have been identified which are suitable for dendrochronology in the tropics. One key strategy mentioned is the value of targeting those species which are closely related to others successfully shown to cross-date elsewhere in the tropics or at higher latitudes (e.g. coniferous species). Trees which are deciduous, with ring porous to semi-ring porous wood anatomy, are often the most promising (e.g. teak and related species). Large diameter cores, $\log$ sections, and achievement of large sample size can facilitate tropical tree-ring efforts for suitable species.

There is a need to integrate tropical tree-ring work with related research on low latitude forests, including studies and modeling of ecology, phenology (including dendrometer measurements), forest dynamics, forest resources, and documentation of any anthropogenic effects. These studies can considerably aid interpretation of the tropical tree-ring efforts and viceversa. It is useful to separate two foci: true tropical dendrochronology (i.e. equatorial to near-equatorial sites) in Southeast Asia and elsewhere as opposed to dendrochronology at high elevations in Asia (e.g. Tibet), the latter being more comparable to temperate studies. There is a slower rate of progress in the tropical efforts, requiring extra encouragement. It is important to note that more temperate sites can also yield information on tropical climate features, for example the demonstrated ENSO signal in tree-ring data from the western USA. Other parameters, in addition to ring width, hold promise for gleaning the maximum possible forest growth and climate information from tropical trees. Those highlighted at the meeting include stable isotopes, maximum latewood density and other intra-ring width and density param-
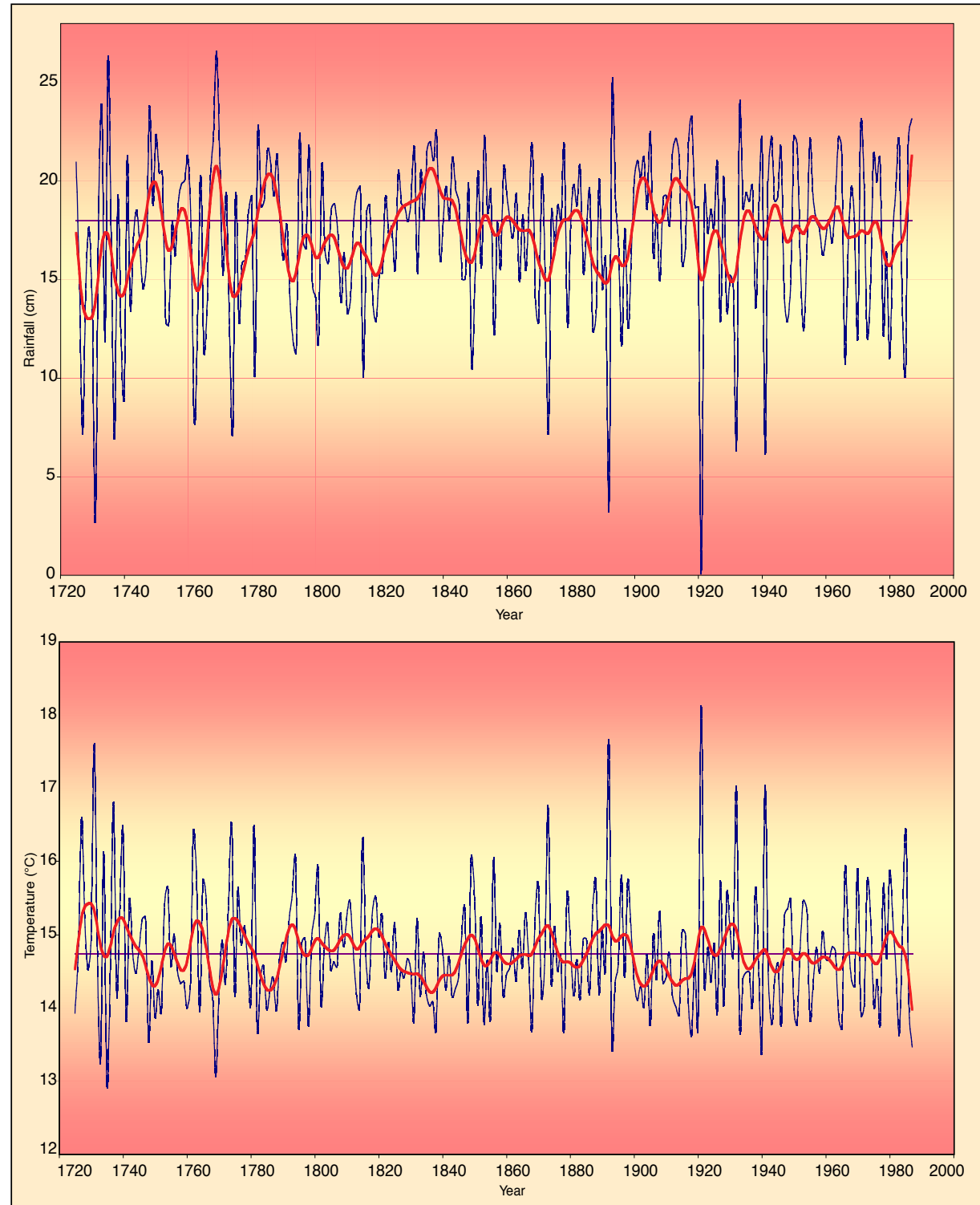

Reconstructed pre-monsoon (March-April-May) climate of Shimla (Western Himalaya, India) using Picea smithiana tree-ring chronologies (smooth lines indicate low-frequency variations)

eters, vessel area and other anatomical features, and electron probe and chemical analyses.

Tropical dendrochronologists should increase the awareness of the potential usefulness of tree-ring data for climatic studies, and collaborate with climatologists to determine how best to exploit the available instrumental climatic data. In addition to correlation and regression analysis of treering and climate data, comparison of tree growth and climate extremes can yield useful information. Efforts should be made to compile local literature on relevant botanical and forest-related knowledge, and to compare the tree-ring data to historical and other proxy records available for the region of interest. Such comparisons can aid in cross-validation and eventual multiproxy climatic reconstructions. The treering data should be submitted to the wider dendrochronological and climate community through the International Tree-Ring Data Bank (ITRDB). There is also a need to compile/assemble a database of proxy, historical and instrumental data for Asia for dissemination to interested scientists.

The papers resulting from the meeting will be published in a journal which will be announced. As a follow-up to the meeting, a small dendroecological fieldweek is planned for local students and scientists in Thailand within the coming year.

This meeting was supported by PAGES and by the Climate Dynamics Division of the United States National Science Foundation.

\section{Rosanne D'Arrigo}

Tree-Ring Laboratory, Lamont-Doherty Earth Observatory, Palisades NY, USA druidrd@|deo.columbia.edu 